\title{
Association of intraocular pressure with
}

\section{cataract surgery}

\begin{abstract}
Zed Janan Petris* Ahmed Ismail Abdulgani** Ahmed Kareem Joma** Eman Hussein Alwan**
\end{abstract}
\section{Abstract}

Background and objective: Cataract and glaucoma are common co-morbidities and are the first and the second leading causes of blindness worldwide. There are many reasons to consider cataract extraction in individuals with cataract. These individuals derive great visual benefit from the increased acuity and improved contrast sensitivity provided by a clear artificial lens. An improvement in vision allows for more accurate visual field monitoring, and a clear optical pathway enhances the quality and reproducibility of optic nerve imaging. This study aimed to determine the association between intraocular pressure with cataract surgery in human eyes by monitoring changes in intraocular pressure in patients who underwent cataract surgery at Hawler Teaching Hospital at Erbil.

Methods: This cross-sectional study was conducted on 71 subjects that underwent cataract surgery at Hawler Teaching Hospital at Erbil city from April 2013 to April 2014. Full ophthalmic examination including intraocular pressure measurement was done to every participant before cataract surgery, one week and one month after surgery.

Results: Paired samples t-test showed highly significance difference $(P<0.001)$ between mean intraocular pressure measurements before, one week and one month after cataract surgery. The average decrease in postoperative intraocular pressure from preoperative intraocular pressure during one month was $2.02 \mathrm{~mm} \mathrm{Hg}(12.39 \%)$.

Conclusion: Cataract surgery reduces intraocular pressure and can be considered as an effective way to manage patients with a concurrence of glaucoma and cataracts.

Keywords: Intraocular pressure; Cataract surgery.

\section{Introduction}

The human lens is crystalline with an inner nucleus of older inactive cells and an outer cortex, the whole being surrounded by the capsule. ${ }^{1}$ The normal lens is transparent, any congenital or acquired opacity in the lens capsule or substance, irrespective of the effect on vision, is a cataract. $^{2}$ According to the (WHO), cataract is the leading cause of blindness and visual impairment throughout the world. In 2002, the WHO estimated that cataracts caused reversible blindness in more than 17 million $(47.8 \%)$ of the 37 millions blind individuals worldwide, and this number is projected to reach 40 million by $2020 .^{3}$ The intraocular pressure (IOP) refers to pressure exerted by intraocular contents on the coats of the eyeball. ${ }^{4}$ In the general population, the mean IOP is $16 \mathrm{~mm} \mathrm{Hg}$; two standard deviations on either side of this give a normal IOP range of $11-21 \mathrm{~mm} \mathrm{Hg}$. Various factors influencing IOP can be grouped including heredity, age, sex, diurnal variation of IOP, postural variation, blood pressure, general anesthetics and many other drugs. ${ }^{6}$ Many studies have demonstrated IOP reduction after cataract surgery. ${ }^{7}$ The most commonly performed type of cataract surgery is referred as phacoemulsification. In this procedure, the dense nucleus of lens is broken up and the pieces are removed by vacuum. ${ }^{8}$ Planned ECCE (extracapsular cataract extraction) is another type of cataract surgery still practiced in most of the centers and is also

* Directorate of Health, Erbil, Iraq

** Department of Surgery, College of Medicine, Hawler Medical University, Erbil, Iraq. 
a basic for advanced procedure. ${ }^{9}$ The aim of this study was to assess the association between IOP changes and cataract surgery in human eyes and to show if cataract surgery can be considered as a safe way to lower IOP. This study aimed to determine the changes in mean IOP measures before and after cataract surgery by measuring IOP before surgery, one week and one month after surgery for every patient included in this study.

\section{Methods}

This cross-sectional study was conducted in the Ophthalmologic Consultation Unit at Hawler Teaching Hospital, Erbil between April 2013 and April 2014. Data was collected from 8:00 am to $1: 00 \mathrm{pm}$ every day during the data collection period. 71 eyes of 71 different cataract patients who have undergone cataract surgery at Hawler Teaching Hospital between April 2013 and April 2014 were included in the study. These patients were of different age groups, both sexes, from different areas within Iraq, from different socioeconomic groups, and they were of different nationalities and religions. Patients with a history of glaucoma, family history of glaucoma, history of previous intraocular surgery or refractive surgery of the same eye and patients who showed serious postoperative complications were excluded from the study. The IOP of all participants was measured preoperatively, one week and one month post cataract surgery by using Goldman applanation tonometry (Goldmann model, Haag streit, Bern, Switzerland). All measurements were done between 8.00 and 9.00 a.m. to avoid diurnal variation. A single reading was taken every time to avoid excessive massage that is applied by tonometry head to the eye that may lower IOP reading. The IOP of all participants was measured by the same device and the same examiner. All eyes included in the study underwent cataract extraction without peripheral iridotomy by the same team. All phaco surgery were done by the same device (OERTLI CataRhex Swisstech Phacoemulsifier /Switzerland). After operation, all patients were kept on tapering dose of the same type of topical steroid and same topical antibiotics for about one month.

\section{Ethical issues}

The study was approved by the Research Ethics Committee at the College of Medicine, Hawler Medical University.

\section{Statistical analysis}

Microsoft Office Excel 2007 was used for data entry. The statistical package for the social sciences (version 16) was used for data entry and analysis. Analysis of variance was performed on the data to examine the means differences among several groups. Paired samples t-test was used to compare mean values of the same sample in two occasions. A $P$ value of $\leq 0.05$ was regarded as statistically significant.

\section{Results}

Of the 71 patients (71 eyes) who were included in the study, $34(47.9 \%)$ were males and $37(52.1 \%)$ were females. Mean $( \pm S D)$ age of our sample was $60.69 \pm 14.195$ years ranging from 9 to 89 years. Of 71 cataract patients, 12 patients $(16.9 \%)$ were diabetic. Sixty-three eyes $(88.7 \%)$ were hypermetropic, six eyes $(8.5 \%)$ were myopic, and only two eyes $(2.8 \%)$ were emmetropic. Forty-five patients $(63.4 \%)$ underwent cataract surgery by ECCE, while 26 patients $(36.6 \%)$ underwent cataract surgery by phacoemulsification. Mean $( \pm S D)$ IOP measurement before cataract surgery was $16.30 \pm 2.900 \mathrm{mmHg}$. Mean ( $\pm S D)$ IOP measurement one week post operation was $15.49 \pm 2.766 \mathrm{mmHg}$. Mean $( \pm S D)$ IOP measurement one month post operation was $14.28 \pm 2.753 \mathrm{mmHg}$. Mean decrease $( \pm S D)$ in IOP measurement one week and one month after surgery was by $0.81 \pm 0.134 \mathrm{~mm} \mathrm{Hg} \mathrm{(4.96 \% )}$ and $2.02 \pm 0.147 \mathrm{mmHg}(12.39 \%)$, respectively. Paired samples t-test showed statistically significant difference between mean IOP 
measurements before and one week after cataract surgery $(P<0.001)$. It also showed statistically significant difference between mean IOP before and one month after cataract surgery $(P<0.001)$ as shown in Table 1 and Figure 1. The mean reduction of IOP after one month from surgery was $2.09 \mathrm{~mm} \mathrm{Hg} \mathrm{(13.06 \% )} \mathrm{for} \mathrm{those}$ patients who underwent ECCE and 1.98 $\mathrm{mm} \mathrm{Hg}(11.77 \%)$ for those patients who underwent phacoemulsification. There was no statistically significant difference in IOP reduction between ECCE and phaco groups (IOP reduced in both groups) as shown in Figure 2.

Table 1: Paired samples t-test of difference of IOP means pre and post cataract surgery.

\begin{tabular}{lllll}
\hline Paired Samples Test & $\mathbf{T}$ & $\mathbf{d f}{ }^{*}$ & Mean decrease in intraocular pressure & $\boldsymbol{P}$ value \\
\hline $\begin{array}{l}\text { Pair 1: preoperative IOPQ } \\
\text { week post operative IOP }\end{array}$ & 7.615 & 70 & $0.81 \pm 0.134 \mathrm{~mm} \mathrm{Hg}$ & $<0.001$ \\
$\begin{array}{l}\text { Pair 2: preoperative IOP } \\
\text { month post operative IOP }\end{array}$ & 10.796 & 70 & $2.02 \pm 0.147 \mathrm{~mm} \mathrm{Hg}$ & $<0.001$ \\
\hline
\end{tabular}

${ }^{*}$ df degree of freedom, ${ }^{Q}$ IOP intraocular pressure, $P<0.05$ is regarded as statistically significant.

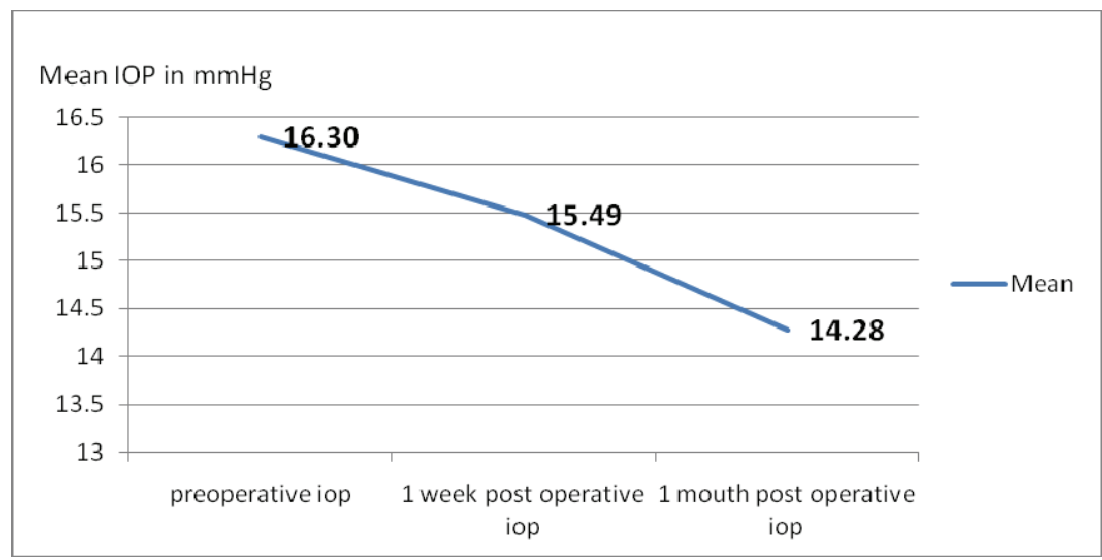

Figure 1: Mean decrease in IOP after cataract surgery within one month.

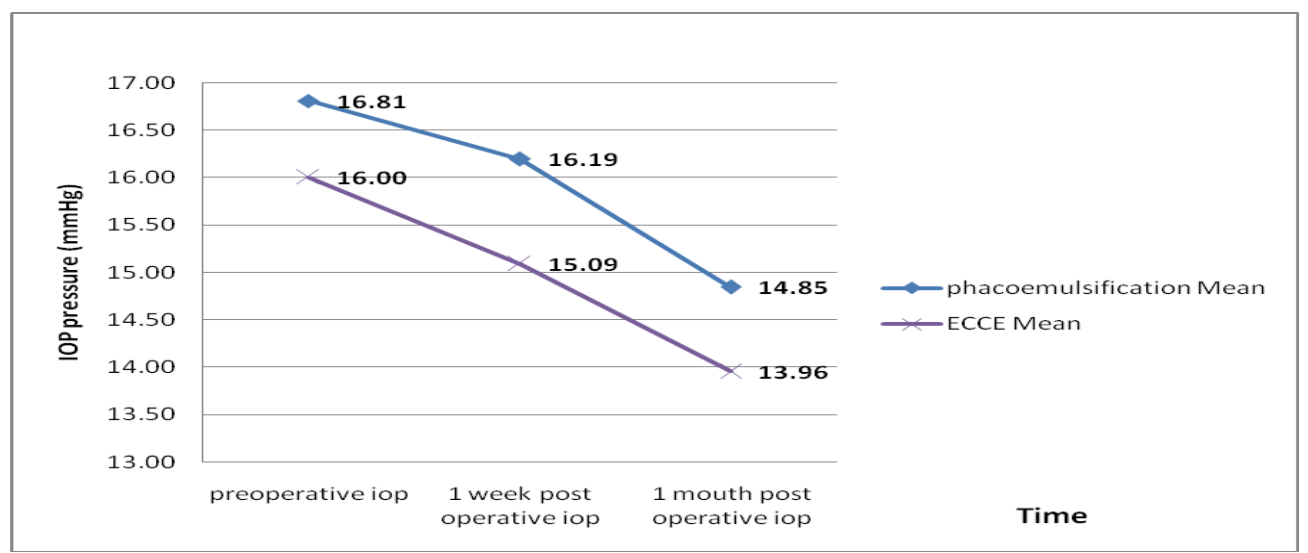

Figure 2: Comparison of mean IOP reduction after 2 type of cataract surgery during one month. 
The mean decrease in IOP after one month was $1.67 \pm 0.127 \mathrm{~mm} \mathrm{Hg}(10.1 \%)$ in myopic eyes and $2.06 \pm 0.148 \mathrm{~mm} \mathrm{Hg}(12.65 \%)$ in hypermetropic eyes with no statistically significant difference between the two groups (Figure 3). The mean decrease in IOP after one month was $1.76 \pm 0.022$ $\mathrm{mm} \mathrm{Hg}(11.16 \%)$ in male patients and $2.24 \pm 0.232 \mathrm{~mm} \mathrm{Hg}(13.34 \%)$ in female patients with no statistically significant difference between them as shown in Figure 4. The mean decrease in IOP after one month was $1.58 \pm 0.186 \mathrm{mmHg}$ $(9.5 \%)$ in diabetics and $2.1 \pm 0.162 \mathrm{mmHg}$ $(12.9 \%)$ in nondiabetics with no statistically significant difference between the two groups as shown in Figure 5.

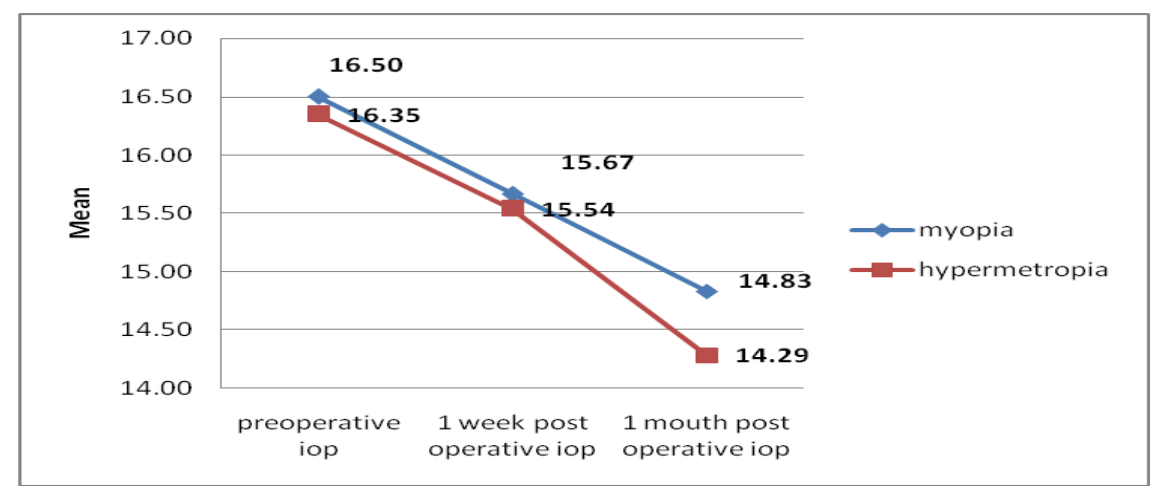

Figure 3: mean IOP changes during one month after cataract surgery in both myopic and hypermetropic eyes.

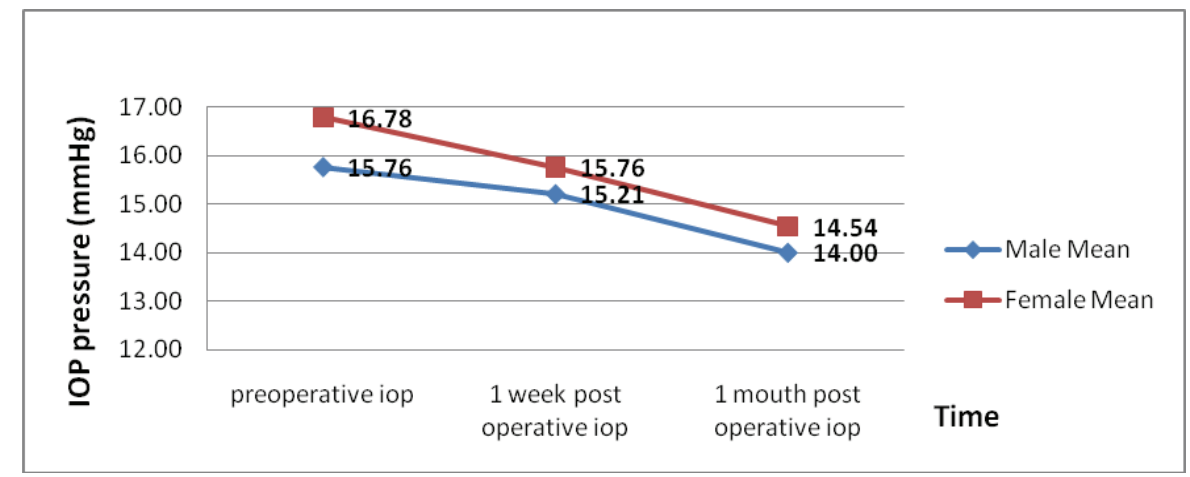

Figure 4: Mean differences in IOP reduction during one month after cataract surgery in both sexes.

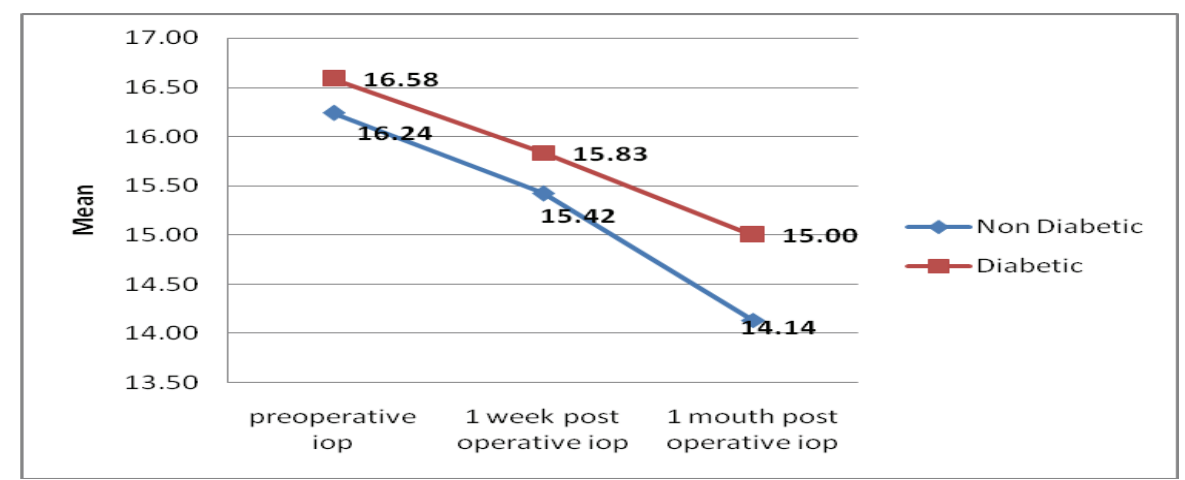

Figure 5: Mean IOP changes during one month after cataract surgery in diabetics and nondiabetics patients. 


\section{Discussion}

Over the past several years, there has been increased interest in the effects of cataract surgery on IOP in glaucoma patients. Many questions about the relationship between cataract surgery and IOP remain. Why does cataract surgery lower IOP? Which patients will have an IOP -lowering response? How strong will that response be? Many studies tried to answer the above questions, and our study was one of them. The earliest studies of IOP after cataract surgery showed little if any reduction of it. $\stackrel{10-12}{-} \mathrm{A}$ study done by Radius et al. in 1984 found that there was a mean increase in intraocular pressure of 0.1 $\mathrm{mmHg}$ following cataract surgery. This increase, however, was not statistically significant. ${ }^{10}$ In contrast, our study found statistically significance difference between mean IOP measurements before, one week and one month after cataract surgery $(16.30 \pm 2.900 \mathrm{mmHg}, 15.49 \pm 2.766 \mathrm{mmHg}$ and $14.28 \pm 2.753 \mathrm{~mm} \mathrm{Hg}$, respectively). However, the above results of earliest studies probably don't apply today because of advances in surgical technique and intraocular lens technology. As extra capsular surgery became the standard, many studies began to demonstrate a lowering of IOP after cataract surgery. An example of these is a study done in California, USA by Tong et al. in 1998 who found that the mean preoperative IOP was $15.8 \mathrm{mmHg}$. It dropped postoperatively by $1.3 \pm 0.2 \mathrm{~mm} \mathrm{Hg}$ at one week $(P<0.001)$, $2.5 \pm 0.2 \mathrm{~mm} \mathrm{Hg}$ at six weeks $(P<0.001) .{ }^{3}$ Our study also found statistically significant $(P<0.001)$ reduction in IOP post cataract surgery and the average decrease in IOP during one month after cataract surgery was $2.02 \pm 0.147 \mathrm{mmHg}(12.39 \%)$. Cho in 2008 also found a statistically significant difference between preoperative and postoperative IOP related to axial length at one day, one week, three weeks, and five weeks after the phacoemulsification. ${ }^{14}$ Some studies found IOP reduction on a sustained basis after cataract surgery; an example is a study done in Denmark by
Hansen et al. in 1995 who found that the mean IOP value 7 years after surgery was $1.3 \mathrm{mmHg}$ lower than the preoperative mean value. No significant difference was found among the values at four months, 2.5 years, and seven years. ${ }^{15}$ Other long-term studies have shown a drop in IOP of about $3 \mathrm{mmHg}$ in POAG patients and nonglaucoma patients with $75-85 \%$ of patients maintaining an IOP reduction at five years, ${ }^{16-20}$ in comparison to our study which showed IOP reduction for just one month post cataract surgery. The method of cataract extraction may influence the reduction of IOP. A study done in California, the USA by Tennen et al. in 1996 found that in the clear corneal incision group ( $\mathrm{n}=84)$, mean IOP was statistically significantly lower $(P=0.019) 12$ months after surgery than preoperatively (13.65 versus $15.57 \mathrm{~mm} \mathrm{Hg}$ ). Although there was a trend toward decreased IOP in the scleral tunnel incision group $(n=51)$, the difference was not statistically significant $(P=0.178) .{ }^{21}$ Another study was done in Italy by Saccà et al. in 2001 on 79 patients who completed the 6 month examination. ECCE resulted in greater reductions in IOP than the other procedures (ECCE: 27\% and $36 \%$ in normal patients and those with POAG, respectively; phacoemulsification: $19 \%$ and $22 \%$, respectively). ${ }^{23}$ Our study showed no statistically significant difference in reducing mean IOP between ECCE and phaco, though. ECCE showed to decrease mean IOP by $13.06 \%$ after one month which is more in comparison to $11.77 \%$ reduction by phaco during the same period, but this difference was statistically insignificant. We can explain our results regarding decreasing IOP after cataract surgery in two ways. Firstly, the facility of aqueous outflow is known to increase after cataract surgery. The angle widening after cataract surgery suggesting improved function of the trabecular meshwork improving aqueous access to the trabecular meshwork. ${ }^{22,23}$ Secondly, cataract surgery typically induces a lowgrade inflammation in the immediate 
postoperative period. It is possible that the induced inflammation lowers IOP by either decreasing the aqueous production of the ciliary body, or it could increase outflow similar to the mechanism of prostaglandin analogues. Little experimental data exists to support these hypotheses. ${ }^{24}$

\section{Conclusions}

Cataract surgery decreases intraocular pressure and can be considered as an effective way to manage patients with a concurrence of glaucoma and cataracts.

\section{Conflicts of interest}

The authors report no conflicts of interest.

\section{References}

1. Jane O, Lorraine C. Ophthalmology at a Glance. $1^{\text {st }}$ edition. UK: Blackwell Science Ltd; 2005. p. 72.

2. Kanski JJ. Clinical ophthalmology A systemic approach. $6^{\text {th }}$ ed. London: Elsevier Science. Butterworth-Heineman; 2006. p. 337.

3. Bobrow JC, Blecher MH, Glasser DB, Mitchell KB, Rosenberg LF, Reich J, et al. Basic and clinical science course: lens and cataract, Section 11. San Francisco, USA: American Academy of Ophthalmology; 2011. P. 71.

4. Khurana AK, Khurana I. Anatomy and physiology of eye. $2^{\text {nd }}$ ed. New Delhi_Bangalore: CBS Publisher and Distributors; 2006. p. 53-71.

5. Kanski JJ. Clinical ophthalmology: A systemic approach. $6^{\text {th }}$ ed. London: Elsevier Science. Butterworth-Heineman; 2006. p. 374-80.

6. Khurana AK. Comprehensive Ophthalmology. $4^{\text {th }}$ ed. New Delhi_Bangalore: New age international (p) limited, publishers; 2007. p. 208-11.

7. Foroozan R, Levkovitch_Verbin H, Habot_Wilner Z, Burla N. Cataract Surgery and Intraocular Pressure. Ophthalmology 2008; 115:104-8.

8. Snell RS, Lemp MA.Clinical anatomy of the eye. $2^{\text {nd }}$ ed. India: Blackwell Science; 1998. p. 203.

9. Sundararajan R. Manual of practical cataract surgery. $1^{\text {st }}$ ed. New Delhi-India; 2009. p.45.

10. Radius RL, Schultz K, Sobocinski K, Schultz RO, Easom H. Pseudophakia and intraocular pressure. Am J ophthalmol 1984; 97:738-42.

11. Bigger JF, Becker B. Cataracts and primary open -angle glaucoma: the effect of uncomplicated cataract extraction on glaucoma control. Trans Amcad Ophthalmol Otolaryngol 1971; 75:260-72.

12. Randolph ME, Maumenee AE, Iliff CE. Cataract extraction in glaucomatous eyes. Am J Ophthalmol 1971; 1:328-30.

13. Tong JT, Miller KM. Intraocular pressure change after sutureless phacoemulsification and foldable posterior chamber lens implantation. J Cataract Refractive Surgery 1998; 24:256-62.
14. ChoYK. Early intraocular pressure and anterior chamber depth changes after phacoemulsification and intraocular lens implantation in non glaucomatous eyes: J Cataract Refrac Surgery 2008; 34:1104-9.

15. Hansen MH, Gyldenkerne GJ, Otland NW, Corydon L, Naeser K. Intraocular pressure 7 years after extracapsular cataract extraction and sulcus implantation of a posterior chamber intraocular lens. J Cataract Refractive Surgery $1995 ; 21: 676-8$.

16. Liu DT, Lee VY, Chiu TY, Lam DS. Long-term intraocular pressure control after clear corneal phacoemulsification in glaucoma patients. J Cataract Refractive Surgery 2006; 32:183.

17. Kim DD, Doyle JW, Smith MF. Intraocular pressure reduction following phacoemulsification cataract extraction with posterior chamber lens implantation in glaucoma patients. Ophthalmic Surgery. Lasers 1999; 30:37-40.

18. Pohjalainen T, Vesti E, Uusitalo RJ, Laatikainen L. Phacoemulsification and intraocular lens implantation in eyes with open-angle glaucoma. Acta Ophthalmol Scand 2001; 79:313-6.

19. Shingleton BJ, Gamell LS, O'Donoghue MW, Baylus SL, King R. Long-term changes in intraocular pressure after clear corneal phacoemulsification: normal patients versus glaucoma suspect and glaucoma patients. J Cataract Refractive Surgery 1999; 25:885-90.

20. Shingleton BJ, Pasternack JJ, Hung JW, O'Donoghue MW.Three and five year changes in intraocular pressures after clear corneal phacoemulsification in open angle glaucoma patients, glaucoma suspects, and normal patients. J Glaucoma 2006; 15:494-8.

21. Tennen DG, Masket S. Short-and long-term effect of clear corneal incisions on intraocular pressure. J Cataract Refractive Surgery 1996; 22:568-70.

22. Hayashi K, Hayashi H, Nakao F, Hayashi $F$. Changes in anterior chamber angle width and depth after intraocular lens implantation in eyes with glaucoma. Ophthalmology 2000; 107: 698-703.

23. Meyer MA, Savitt ML, Kopitas E. The effect of phacoemulsification on aqueous outflow facility. Ophthalmology 1997; 104:1221-7.

24. Yousufzai SY, Ye Z, Abdel_Latif AA. Prostaglandin $F_{2}$ alpha and its analogs induce release of endogenous prostaglandins in iris and ciliary muscles isolated from cats and other mammalian species. Exp Eye Researches 1996; 63:305-10. 